\title{
Electricity metering and backup power supply for multi-storey buildings
}

\author{
Aktam Denmukhammadiev ${ }^{1 *}$, Almardon Mustafoqulov ${ }^{1}$, Himalokhon Valikhonova ${ }^{1}$, Erkin \\ Sobirov ${ }^{1}$ and Temur Raimov ${ }^{2}$ \\ ${ }^{1}$ Tashkent institute of irrigation and agricultural mechanization engineers, Tashkent, Uzbekistan \\ ${ }^{2}$ Tashkent University of Information Technologies named after Muhammad Al-Khwarizmi, Tashkent, \\ Uzbekistan
}

\begin{abstract}
The city of Tashkent is developing at a very fast pace, and the power supply of a new type is the subject of innovation in this direction. Commercial metering of electricity in multi-storey buildings in modern cities mainly solves the current payment problems for consumed electricity. And the main disadvantages of such networks will remain overboard. Technically competently control the common highway of a multi-storey building is necessary. Here, the commercial metering of electricity consumption does not solve the technical policy considering the development of the city. The construction of multi-storey buildings based on an individual project is growing rapidly in the city. Together with the environmental aspects of the impact of such buildings, it is necessary to address the issue of reliability in power supply. The use of power supply schemes taking into account backup power is relevant. It is proposed to take a diesel power plant as a backup source. For this, an electrical circuit of relay protection using an automatic transfer switch is proposed.
\end{abstract}

\section{Introduction}

Grid organizations provide commercial metering of electrical energy (power) about objects directly or indirectly connected to their networks (except for the replacement of collective (common house) electricity meters); Suppliers of last resort provide commercial metering of electrical energy (capacity) in respect of apartment buildings located in the area of their activity (except for premises of apartment buildings, the power supply of which is carried out without the use of common property), including the installation of collective (general building) electricity meters.

\footnotetext{
*Corresponding author: aquvvat@mail.ru
} 
Table 1. Reference data for electrical consumers

\begin{tabular}{|c|c|c|c|c|}
\hline № & Name of the consumer & Power & $\cos \phi$ & $\operatorname{tg} \phi$ \\
\hline \multirow[t]{5}{*}{1} & Standard AD under load & $0 \%$ & 0.17 & 5.80 \\
\hline & & $25 \%$ & 0.55 & 1.52 \\
\hline & & $50 \%$ & 0.73 & 0.94 \\
\hline & & $75 \%$ & 0.80 & 0.75 \\
\hline & & $100 \%$ & 0.85 & 0.62 \\
\hline 2 & Incandescent lamp & & $\approx 1$ & $\approx 0$ \\
\hline 3 & Fluorescent lamps & & $\approx 0.5$ & $\approx 1.73$ \\
\hline 4 & Discharge lamps & & $0.4-0.6$ & $\begin{array}{l}\approx 2.29- \\
1.33\end{array}$ \\
\hline 5 & Resistance furnaces & & $\approx 1$ & $\approx 0$ \\
\hline 6 & $\begin{array}{l}\text { Induction ovens (with } \\
\text { compensation) }\end{array}$ & & 0.85 & 0.62 \\
\hline 7 & Dielectric heating plants & & 0.85 & 0.62 \\
\hline 8 & $\begin{array}{l}\text { Contact electric welding } \\
\text { devices }\end{array}$ & & $0.8-0.9$ & $0.75-0.48$ \\
\hline 9 & $\begin{array}{l}\text { Single-phase static arc } \\
\text { welding machines }\end{array}$ & & $\approx 0.5$ & $\approx 1.73$ \\
\hline 10 & $\begin{array}{l}\text { Rotating arc welding } \\
\text { machines }\end{array}$ & & $0.7-0.9$ & $1.02-0.48$ \\
\hline 11 & Arc furnaces & & 0.80 & $2.25-0.75$ \\
\hline 12 & Thyristor power rectifiers & & $0.4-0.8$ & $1.02-0.48$ \\
\hline & $\begin{array}{l}\text { Household electrical } \\
\text { appliances: }\end{array}$ & & & \\
\hline 13 & Electric stove & $\begin{array}{l}1200- \\
6000\end{array}$ & 1.0 & 0.0 \\
\hline 14 & Heater & $\begin{array}{l}500- \\
2000\end{array}$ & 1.0 & 0.0 \\
\hline 15 & Vacuum cleaner & $\begin{array}{l}500- \\
2000\end{array}$ & 0.9 & 0.48 \\
\hline 16 & Iron & $\begin{array}{l}1000- \\
2000\end{array}$ & 1.0 & 0.0 \\
\hline 17 & Televisor & $100-400$ & 1.0 & 0.0 \\
\hline 18 & Hair dryer & $\begin{array}{l}600- \\
2000\end{array}$ & 1.0 & 0.0 \\
\hline 19 & Refrigerator & $150-600$ & 0.9 & 0.48 \\
\hline 20 & Electric kettle & $\begin{array}{l}1000- \\
2000\end{array}$ & 1.0 & 0.0 \\
\hline 21 & Microwave oven & $\begin{array}{l}700- \\
2000 \\
\end{array}$ & 1.0 & 0.0 \\
\hline 22 & Washing machine & $\begin{array}{l}1500- \\
2000\end{array}$ & 0.9 & 0.48 \\
\hline
\end{tabular}

In modern urban planning, the power supply of multi-storey buildings is an urgent task.

Researchers have addressed the issues of optimizing the complex parameters of the urban distribution of the electrical network by optimizing some standard cross-sections of cable lines[1,2,3,4]. Thus, the construction of the DN at an electrical load density $\delta \geq 10$ MW / km2 is economically feasible with a single (unified) cable cross-section. It is recommended to use in the DN up to $1000 \mathrm{~V}$ section of $120 \mathrm{~mm}^{2}$. And with load densities $\delta<10 \mathrm{MW} / \mathrm{km}^{2}$, it is optimal to use $2 \div 3$ cable sections. In this case, it is recommended, depending on the density of the electrical load, to apply a section of the head section of lines up to $1000 \mathrm{~V}-185,150$ and $120 \mathrm{~mm} 2$, and sections of subsequent sections - on a 
scale of standard sections with a ratio of adjacent sections $1.8 \div 2.0$. Optimization of parameters shows that building a DN up to $1000 \mathrm{~V}$ for large load densities is economically feasible with a limited number of sections and for small load densities with less stringent restrictions on the number of applied sections. It is necessary to indicate that the obtained results are intermediate since they are obtained without considering stability, and the zone is equal to the economic efficiency. The study of the stability of the technical-economic (cost) model of the DN up to $1000 \mathrm{~V}$ in the area of its minimum implies an analysis of the applicability of discrete standard values of economic parameters in the field of economic efficiency of the technical-economic function, the need or the possibility of using additional criteria for a unique choice of parameters (i.e. optimization taking into account unification) and creates prerequisites for further unification of these parameters[1-4].

Future Extend It is necessary to indicate that the obtained results are intermediate since they are obtained without considering stability, and the zone is equal to the economic efficiency. The study of the stability of the technical-economic (cost) model of the DN up to $1000 \mathrm{~V}$ in the area of its minimum implies an analysis of the applicability of discrete standard values of economic parameters in the field of economic efficiency of the technicaleconomic function, the need or the possibility of using additional criteria for a unique choice of parameters (i.e. optimization taking into account unification) and creates prerequisites for further unification of these parameters [4].

Table 2. Comparative table for different periods of consumption

\begin{tabular}{|c|c|}
\hline 2-room apartment (for 4 people) & 2-room apartment (for 4 people) \\
\hline $1970 \mathrm{~s}$ & $2020 \mathrm{~s}$ \\
\hline $\begin{array}{l}\text { 1. Incandescent lamp }-4 \text { PCS x } 100=400 \mathrm{Vt} \text {. } \\
\cos \phi=1.0\end{array}$ & $\begin{array}{l}\text { 1. Incandescent lamp }-4 \text { PCS x } 18=72 \mathrm{Vt} \text {. } \\
\cos \phi=1.0\end{array}$ \\
\hline 2. Iron $-1000 \mathrm{Vt} . \cos \phi=1.0$ & 2. Iron $-600 \mathrm{Vt} \cdot \cos \phi=1.0$ \\
\hline 3.TV-160 Vt(4\%). $\cos \phi=1.0$ & 3. $\mathrm{TV}-120 \mathrm{Vt}(103 \%) \cdot \cos \phi=1.0$ \\
\hline 4. Vacuum cleaner - no & 4. Vacuum cleaner $-100 \% \cdot \cos \phi=1.0$ \\
\hline 5. Computer (PC) - no & 5. Computer (PC) $-30-40 \% \cdot \cos \phi=1.0$ \\
\hline \multirow[t]{5}{*}{ 6. Washer $50 \% \cdot \cos \phi=1.0$} & 6. Washer $100 \% \cdot \cos \phi=1.0$ \\
\hline & $\begin{array}{l}\text { 7. Power supply unit (for bodies)-2 PCS. } \\
\cos \phi=1.0\end{array}$ \\
\hline & 8. Microwave 1 PCS. $\cos \phi=1.0$ \\
\hline & 9. Toaster 2 PCS. $\cos \phi=1.0$ \\
\hline & 10. Mixer 2 PCS. $\cos \phi=1.0$ \\
\hline Linear automaton $-10 \mathrm{~A}$ & Linear automaton $-25 \mathrm{~A}$ \\
\hline
\end{tabular}

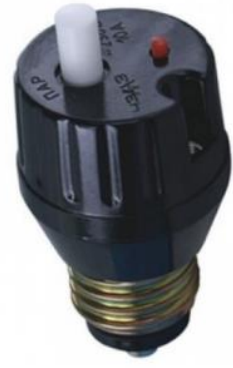

a

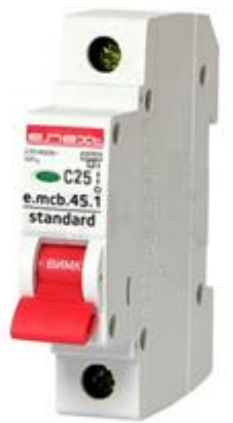

b

Fig.1. Switching devices up to $1000 \mathrm{~V}$ : a is automatic fuse up to $10 \mathrm{~A}, \mathrm{~b}$ is circuit breaker up to $25 \mathrm{~A}$ 
From the above table, it can be seen that over a certain period, the consumption of electrical energy has changed in the direction of increasing the power and character of the consumer. In the 1970s, on a two apartment building, a linear machine for $10 \mathrm{~A}$, then years later, the same consumer has a linear machine $25 \mathrm{~A}$. The power, quantity and power factor of the consumer also change. In general, we have considered the issue of backup supply, but the second supply does not include a diesel power supply $[5,6]$.

The subject of study is the urban electrical loads of multi-storey buildings. The basis for a rational solution to a set of issues related to the design and operation of electrical networks of all voltage classes is quantitative information about electrical loads. Determination of electrical loads is the first stage in the design of a city power supply system. According to the magnitude of electrical loads, the electrical equipment of the power supply system is selected and checked, power and electricity losses are determined. Capital costs for the power supply system, operating costs, reliability of electrical equipment and development prospects, taking into account changes in the nature of the loads, depending on the correct assessment of the predicted loads.

\section{Methods}

Knowledge of the methods for calculating electrical loads is absolutely necessary both in the design of the power supply system and in the operation of existing electrical networks since new consumers often appear who want to obtain permission to connect to existing electrical networks. Methods for calculating electrical loads for urban, industrial and rural networks have their characteristics, which the electrical engineer also needs to know $[7,8,9]$.

Idle running of the transformer is unprofitable for the city network; it is better to load the power transformer $10-15 \%$ for advertising boards to create the necessary amount for operating and basic (balance) costs. For example, a commercial payment for one apartment is not enough to replace a trunk cable. On the other hand, the non-commercial control of the same highway helps prevent major accidents here.

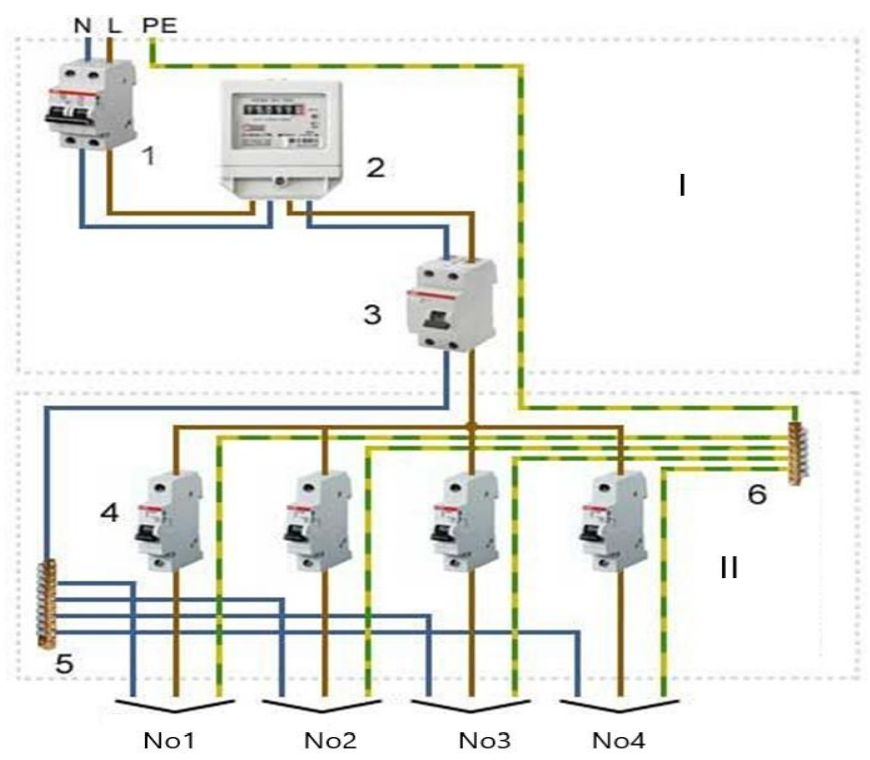

Fig. 2. Wiring diagram for connecting one apartment 
I. Introductory electrical panel at home: 1. Input safety switch, 2. Electric meter, 3. Residual current device (RCD), 4. Single pole type circuit breaker, 5. Zero tire, 6. Grounding tire. II. Electrical panel inside the house. No1, No2, No3, No4 consumers inside the apartment.

Such a transition is possible only if all consumers are fully provided with a stable power supply throughout the entire 24 hours.

As the Ministry of Energy has repeatedly reported, several projects are currently being implemented to increase electricity production and ensure a stable energy supply throughout the country. Then it will be possible to resolve the issue of introducing differentiated tariffs. How exactly did the implemented projects help solve the issue of stability of the country's energy supply?

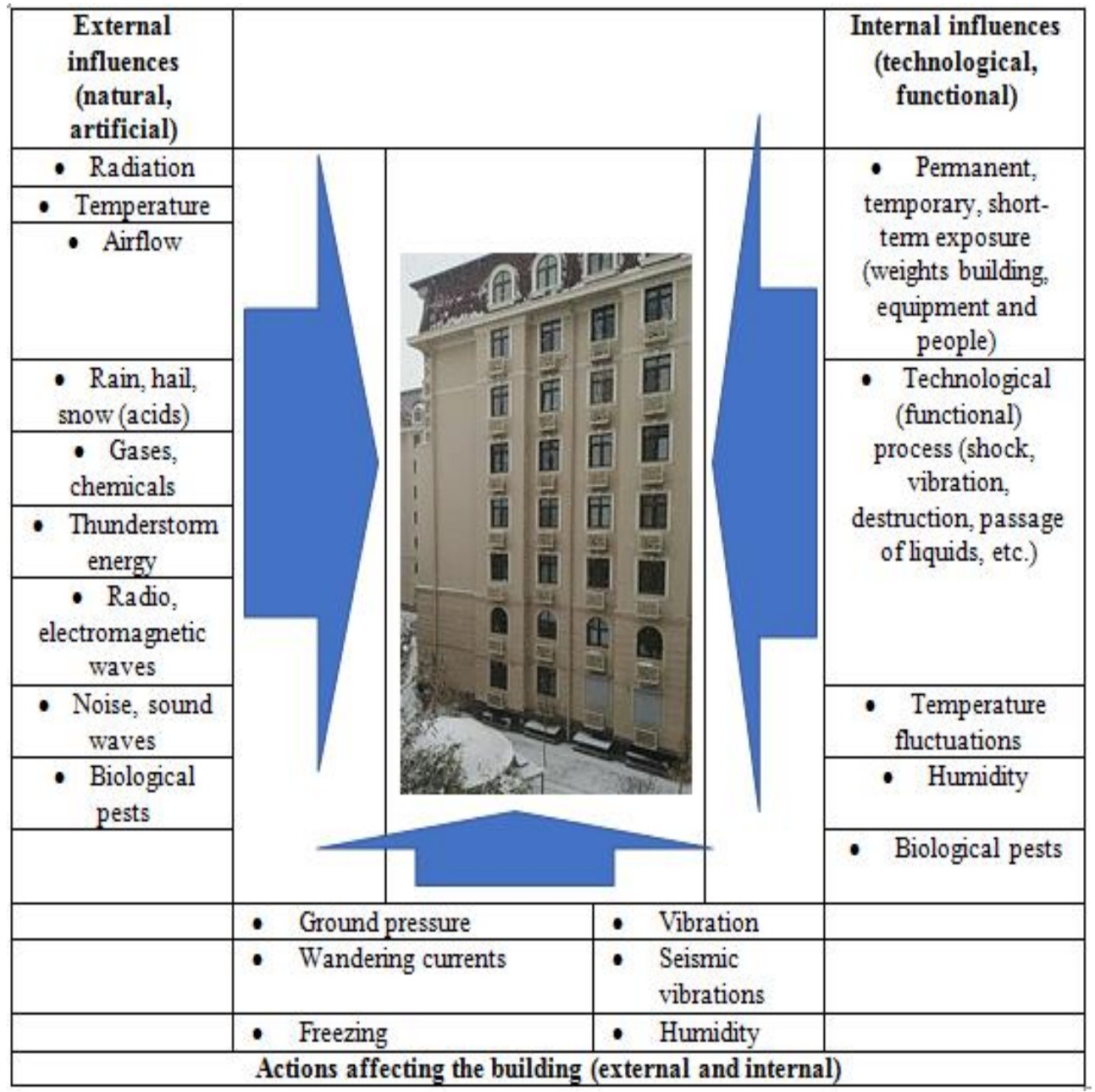

Fig.3. Shows in detail the main influences affecting the building (external and internal).

These influences negatively affect the quality of the building and accelerate the aging of the building.

There is one of the significant drawbacks in the operation of multi-storey buildings designed according to individual plans in Tashkent. This is a power outage of the main 
power supply. New individual objects are more often fed with electrical energy unilaterally; that is, there is no backup power supply.

We offer an electrical circuit using an automatic transfer switch system. At the same time, it is planned to install a diesel power plant of appropriate capacity as a backup source of electrical energy. Below (Figure 4) is a single-line electrical diagram of an automatic transfer switch.

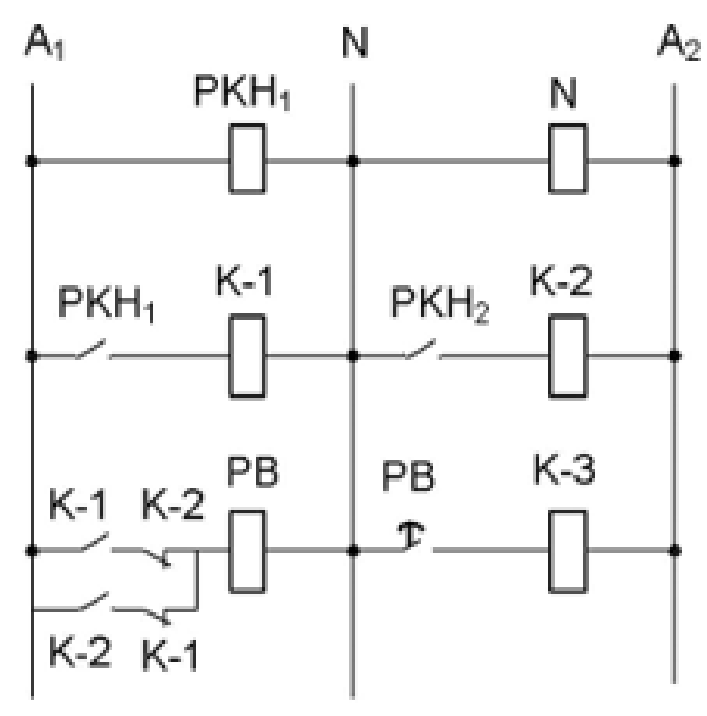

a

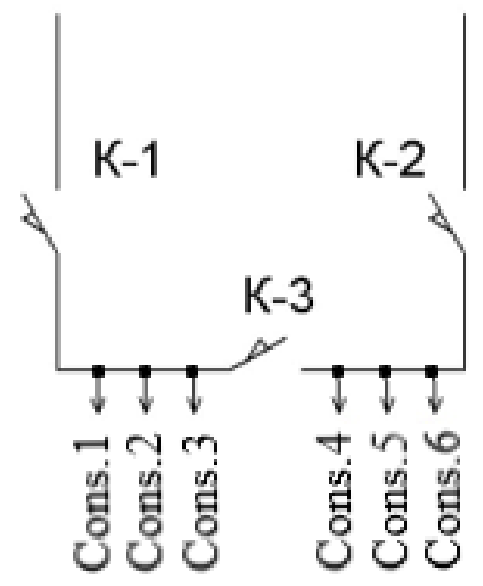

b

Fig.4. Single-line electrical diagram of automatic transfer switch: $a$ is relay protection circuit; $b$ is power circuit diagram.

In modern residential buildings, communication systems operate in an automated mode. These include hot and cold water and heat supply systems, gasification systems, alarm and fire extinguishing systems, Internet and telephone systems, etc.

When using the proposed power supply scheme, high reliability is ensured. According to the proposed scheme (Figure 4. image a) A1 is connected to the main power supply, and 
A2 is connected to the reserve one (for example, to a diesel power station). The automatic backup power input circuit works as follows. The time relay waits for the moment (time) when A1 is completely disconnected, and the automatic reclosing of this line will not restart (i.e. the main line does not restore its power supply). Only then will the backup line be switched on.

\section{Results and Discussions}

All these issues can be resolved through the electric meter of each consumer. Accounting for electricity to identify additional reserves in the power supply of a common house when computerized with software allows you to identify additional capabilities of the common highway, taking into account all changes. This requires the additional installation of a noncommercial electricity meter. Here, when drawing up the program, attention should be paid to the optimization of commercial and non-commercial accounting to economically operate the networks.

As world demand for energy continues to increase, prices will inevitably rise, and many people will find themselves facing stark choices concerning energy-related activities such as transportation, food supplies, and residential heating. Energy efficiency can be defined as the ratio between energy consumed and energy produced. In other words, it is the ability to perform the same function with less energy the goal of any energy management system. It is projected that by 2030, 5 billion people will live in urban areas throughout the world (United Nations, 2001) [10-12]. As buildings become more energy efficient, small power equipment such as computers is an increasingly significant source of energy end-use [13]. Ventilation plays a crucial role in promoting the comfort and health of building occupants. It is sometimes costly in terms of energy consumption but can also be beneficial from an energy perspective when free cooling is available [14]. EV availability, including its position and battery condition, is provided by the vehicle information system [15].

A well-designed battery management system with a set of current and voltage sensors is required to properly monitor the characteristics of the battery to monitor the supply system. It is necessary to develop a reliable and robust diagnostic scheme in case of malfunctions in the operating sensors [16]. Vehicle performance varies abruptly other than nearby room temperatures, and at a higher temperature, fuel economies are found to be better compared to the lower temperature. But, usage of battery at high temperatures for a longer time reduces its life and diminishes vehicle performance [17]. The strategy ensures that the output voltage can be regulated tightly against different loads and wide input variation, and a high-quality input current can be achieved [18]. Sustainable building practices can considerably reduce building's environmental impact on energy consumption. Covering a building envelope with green vegetation, such as a green roof and green wall, is considered a sustainable construction practice, as green vegetation has a positive performance in energy savings [19]. Also, the availability of spare materials ensures the reliable operation of weaving mills and ensures quality operation of looms. The yarns do not break; thus, some non-woven areas are woven as well [20]. To take advantage of this recommended method, you can purchase spare diesel electric motors from various specialized retail stores [21].

\section{Conclusions}

Many countries have differentiated electricity tariffs. They allow you to introduce a flexible tariff scheme and, accordingly, electricity payment. The consumer has the right to conclude contracts at different tariffs for daytime zones (as a rule, when electricity is cheaper at 
night) or at a single tariff (at the same price for electricity in the daytime). Also, a consumption-based stratified tariff is applied (using the base rate). We have proposed a scheme for automatic transfer of the reserve, which unmistakably switches on the reserve power (for example, a diesel power plant). In general, a reliable connection of the uninterruptible power supply will be ensured.

\section{References}

1. Taslimov A.D., and Rakhmonov I.U. Optimization of complex parameters of urban distribution electric networks. J. Phys.: Conf. Ser. 1399, 055046. (2019)

2. A.D. Taslimov, A.S. Berdishev, M.V. Melikuziev and F.M. Rakhimov. Method of choosing the unification of cable sections of electric network cables under conditions of load development uncertainty. Rudenko International Conference "Methodological problems in reliability study of large energy systems" (RSES 2019).

3. A.D. Taslimov, A.S. Berdishev, M.V. Melikuziev and F.M. Rakhimov. Method of selecting parameters of cable lines distributive networks $10 \mathrm{kv}$ in uncertainty conditions. Rudenko International Conference "Methodological problems in reliability study of large energy systems" (RSES 2019).

4. Abdurahim D Taslimov, Rustam J.Baratov. Optimization of Complex Parameters of Urban Electrical Distribution Networks. Journal of Scientific and Engineering Research, 6 (2) pp. 88-92, (2019)

5. Denmukhammadiev A.M., Kodirov I.N., Beytullaeva R.Kh., Khuzhakeldiev B.K., D.Mamedova. To fulfill the requirements for the reliability of power supply for educational institutions. Bulletin of Tashkent State Technical University. (4). pp.6163.(2008)

6. Zakariukin V.P., Kriukov A.V., Shul'gin M.S. Parametric identification of power transformers, Vestnik IrGTU - Proceedings of Irkutsk State Technical University, 12 (59), pp.219-227, (2011)

7. Zakariukin V.P., Kriukov A.V., Shul'gin M.S. Parametric identification of power transformers in phase coordinates, Modern technologies. System analysis. Modeling, 2011, No.4, pp.141-147.(2011).

8. Leonhard.W. Control of electrical drives, Springer Science and Business Media, (2001).

9. Smith J.W., W. Sunderman R. Dugan, and B. Seal. "Smart inverter volt/var control functions for high penetration of PV on distribution systems," in Power Systems Conference and Exposition (PSCE), IEEE/PES, pp. 1-6. (2011).

10. Thomas Dittrich, Tadiran Batteries. Battery concepts for smart utility meters - The requirements and proving their suitability.

11. Jean-Paul Genet and Cliff Schubert. Disining a matering system for small and medium-sized buildings. Schnider electric.

12. Mir Ali, Paul Armstrong. Overview of Sustainable Design Factors in High-Rise Buildings. ctbuh.org/papers.

13. A.C.Menezes, A.Cripps, R.A.Buswell, J.Wright, D.Bouchlaghem. Estimating the energy consumption and power demand of small power equipment in office buildings, Energy and Buildings. 75, pp.199-209. (2014)

14. Adams Rackes, Michael S.Waring. Using multiobjective optimizations to discover dynamic building ventilation strategies that can improve indoor air quality and reduce energy use, Energy and Buildings, 75, pp. 272-280, (2014) 
15. Muhammad Aziz Takuya Oda Takao Kashiwagi. Extended Utilization of Electric Vehicles and their Re-used Batteries to Support the Building Energy Management System. Energy Procedia Volume 75, pp. 1938-1943, (2015)

16. Hong Wen He, Zhen Tong Liu, Yin Hua. Adaptive Extended Kalman Filter Based Fault Detection and Isolation for a Lithium-Ion Battery Pack. Energy Procedia, 75, pp.1950-1955, (2015)

17. Aishwarya Panday, Hari Om Bansal. Hybrid Electric Vehicle Performance Analysis Under Various Temperature Conditions. Energy Procedia, 75, pp. 1962-1967, (2015)

18. Zhuang Xu. An Indirect Space-vector Modulated Three-phase AC-DC Matrix Converter for Hybrid Electric Vehicles, Energy Procedia., 75, pp. 1968-1974, (2015)

19. H.Feng, K.Hewage. Energy saving performance of green vegetation on LEED certified buildings. Energy and Buildings, 75, pp. 281-289, (2014)

20. Baratov R., Pirmatov N., Panoev A., Chulliyev Y., Ruziyev S., and Mustafoqulov A. Achievement of electric energy savings through controlling frequency convertor in the operation process of asynchronous motors in textile enterprises, IOP Conf. Series: Materials Science and Engineering1030, (2021) 